\title{
Public drug injecting in London, Ontario: a cross-sectional survey
}

\author{
Ayden Scheim BA, Beth Rachlis PhD, Geoff Bardwell PhD, Sanjana Mitra MPH, Thomas Kerr PhD
}

\section{Abstract}

Background: Harms associated with public drug injection in large cities are well-established, but little is known about challenges that public injecting may pose for smaller municipalities. We evaluated the prevalence and correlates of public injecting among a sample of people who inject drugs in London, a mid-sized city in southwestern Ontario.

Methods: Between March and April 2016, a sample of people who injected drugs participated in a quantitative survey as part of the Ontario Integrated Supervised Injection Services Feasibility Study. Bivariable and multivariable logistic regression models estimated associations of sociodemographic characteristics, sociostructural exposures and drug use behaviours with regular public injecting (injecting in public $\geq 25 \%$ of the time over the previous $6 \mathrm{mo}$ ). We also described the locations and rationales provided for public injecting.

Results: A total of 196 participants (38.3\% female, median age $39 \mathrm{yr}$ ) provided complete data. Of the 196, 141 (71.9\%) reported any public injecting in the previous 6 months, and 91 (46.4\%) injected in public regularly. Homelessness or unstable housing (adjusted odds ratio [OR] 2.04, 95\% confidence interval [Cl] 1.01-4.12) and frequently injecting opioids (adjusted OR 2.27, 95\% Cl 1.17-4.42) or crystal methamphetamine (adjusted OR $2.38,95 \% \mathrm{Cl} 1.18-4.79$ ) daily were independently associated with regular public injection. Convenience (98 participants [69.5\%]) and homelessness (56 [39.7\%]) were the most commonly reported reasons for public injecting.

Interpretation: As in large cities in Canada, public injecting in London is common and appears to be associated with unstable housing and high-intensity injecting. These results indicate an urgent need to create safer environments for people who inject drugs in London, including supervised injection, to reduce the negative individual and community impacts of public injecting.

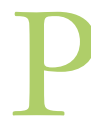
ublic drug injection remains a source of substantial individual and community harm in settings throughout the world. In the Canadian context, high levels of public injecting have been documented among people who inject drugs in Vancouver ${ }^{1-3}$ Ottawa, ${ }^{4}$ Toronto ${ }^{5}$ and Montréal, ${ }^{6}$ where $54 \%-77 \%$ of people who inject drugs reported any recent public injecting, and $17 \%-23 \%$ reported injecting predominantly in public. Public injecting poses the risks of discovery by police, robbery and violence. These immediate risks to individual safety and to one's drug supply are compounded by health risks related to unsafe injection practices and contribute to hasty injection and reduced ability to ensure safety and hygiene. ${ }^{7-9}$ Public injecting tends to be concentrated among the most vulnerable people who inject drugs, being independently associated with homelessness, recent incarceration, high-intensity drug use (e.g., injecting daily or more) and injecting-related risks (e.g., nonfatal overdose, needle-sharing, not cooking and filtering drugs) in several large Canadian cities..$^{1-4,6,10,11}$ At a community level, public injecting is perceived as a threat to public order and contributes to improper disposal of injection-related litter. ${ }^{12}$

Although these public health and order challenges posed by public injecting in major urban centres are well-documented, little is known about challenges that public injecting may pose for smaller municipalities. In the current study, we examined public injecting in London, a mid-sized city in southwestern Ontario located about halfway between Toronto and Detroit. London is Canada's 15th-largest city, with a population of around 370000 in $2011 .^{13}$ Statistics Canada estimates that one-third of Canadians live in cities characterized as London's "peer group." ${ }^{14}$ However, London

\section{Competing interests: None declared.}

This article has been peer reviewed.

Correspondence to: Thomas Kerr, uhri-tk@cfenet.ubc.ca

CMAJ Open 2017. DOI:10.9778/cmajo.20160163 
appears to bear a disproportionate burden of injection drug use and related harms. ${ }^{15}$

Needle and syringe programs in London distributed over 2.5 million clean needles in 2014. ${ }^{16}$ Concern has consistently been expressed regarding public drug use and discarded injection equipment in London's core. ${ }^{17}$ A 2012 Public Health Agency of Canada survey revealed higher levels of injecting of nonprescribed opioids (75\%) and hepatitis C infection (79\%) among people who inject drugs in this city than the national averages. ${ }^{18}$ In 2012, London's health region recorded deaths related to prescription opioids at twice the provincial rate. ${ }^{19}$ In recent years, the number of deaths due to overdose in London has declined, potentially related to a shift toward crystal methamphetamine use among people who inject drugs. ${ }^{20}$ In 2015 , the city experienced an outbreak of new HIV diagnoses among people who inject drugs, who accounted for two-thirds of new HIV diagnoses in London's health unit, compared to $12 \%$ provincially. ${ }^{15}$

These data point to the need for enhanced efforts to identify and prevent drug-related individual and community harms in London and similar mid-sized communities. Therefore, among a sample of people who inject drugs in London, we sought to 1) evaluate the prevalence of recent regular public injecting and associations with sociodemographic characteristics, sociostructural exposures and drug use behaviours, and 2) describe the locations and rationales provided for public injecting.

\section{Methods}

\section{Setting and design}

We obtained data from the Ontario Integrated Supervised Injection Services Feasibility Study, a cross-sectional survey of people who inject drugs in London and Thunder Bay, Ont. The present study focuses on London data only.

\section{Recruitment}

Survey data were collected between March and April 2016 by 3 peer research associates. Eligible participants were aged 18 years or more and reported injecting drugs within the previous 6 months. Based on consultation with expert advisors, including local health care providers and peer research associates, a targeted recruitment strategy was developed. Potential participants were recruited through outreach by peer research associates (on the street and in venues people who inject drugs are known to frequent), recruitment flyers posted in local health and social service agencies, and word-of-mouth (including peer-to-peer distribution of wallet-sized cards). Survey interviews took place at 3 community agencies (including 1 organization that serves women only) across 2 neighbourhoods in London's core. Participants provided written informed consent and were provided a $\$ 25$ honorarium.

\section{Data collection}

The questionnaire, which was administered by an interviewer, was adapted from previous studies of supervised injection feasibility, ${ }^{21}$ programmed on electronic tablets and pretested for clarity and functionality. Survey questions pertained to sociodemographic characteristics, drug use behaviours, health conditions and use of health care services, overdose experiences, and willingness to use and design preferences for supervised injection services. A copy of the questionnaire is included as Appendix 1 (available at www.cmajopen.ca/content/5/2/ E290/suppl/DC1).

\section{Measures}

Participants were asked, "In the last 6 months, how often did you inject in public or semi-public areas like a park, an alley or a public washroom?" Response options included never, occasionally (less than $25 \%$ of the time), sometimes (25\%-74\% of the time), usually ( $\geq 75 \%$ of the time) or always. Responses were categorized to create variables indicating any public injection (yes v. no) and regular public injection (our outcome), defined as yes (v. no) if respondents indicated injecting in public sometimes or more often $(25 \%-100 \%$ of the time). Data were also collected on specific locations in which participants injected in the previous 6 months, rationales for injecting in public and use of outdoor water sources to prepare drugs or rinse syringes.

Sociodemographic characteristics and sociostructural exposures included age (in years), gender (male v. female; transgender participants were categorized based on self-reported gender identity), ethnicity (white v. Indigenous/person of colour), and homelessness or unstable housing, incarceration, drug selling (reporting "selling drugs" as a source of income) and engaging in sex work (including exchanging sex for goods) over the previous 6 months (all yes v. no).

Participants were asked in which London neighbourhood they injected most often. Two responses - downtown and Old East (a lower-income, primarily residential neighbourhood adjacent to downtown) - were endorsed by $79 \%$ of respondents and were thus included as dichotomous variables (usually injects in specified neighbourhood v. usually injects elsewhere). Drug use behaviours included frequent opioid injection and frequent crystal methamphetamine injection (both daily v. less often) to reflect the dominant classes of drugs used by the sample. Other drug use characteristics included usually injecting alone (always or usually v. less often over the previous $6 \mathrm{mo}$ ), needing help injecting over the previous 6 months (yes v. no), syringe sharing in the previous 6 months (borrowing and/or lending v. neither), ever overdosing unintentionally (yes v. no) and ever accessing treatment for substance use (yes v. no).

\section{Statistical analyses}

All analyses were conducted with the use of SAS version 9.4. We stratified descriptive statistics for sociodemographic characteristics, sociostructural exposures and drug use behaviours by recent regular public injecting, and used bivariable logistic regression models to evaluate associations. To adjust for potential confounding, we entered variables associated with regular public injecting at $p<0.05$ in bivariate analyses into a multivariable logistic regression model. As few data were missing, we used complete case analysis, resulting in a sample size of 194 for multivariable logistic regression. 


\begin{tabular}{|c|c|c|c|c|}
\hline \multirow[b]{3}{*}{ Characteristic } & \multicolumn{3}{|c|}{ No. $(\%)$ of participants ${ }^{*} \dagger$} & \multirow[b]{3}{*}{$\begin{array}{c}\text { OR } \\
(95 \% \mathrm{Cl})\end{array}$} \\
\hline & \multirow[b]{2}{*}{$\begin{array}{l}\text { Full sample } \\
\qquad n=196\end{array}$} & \multicolumn{2}{|c|}{ Recent regular public injecting $\ddagger$} & \\
\hline & & $\begin{array}{c}\text { Yes } \\
n=91\end{array}$ & $\begin{array}{c}\text { No } \\
n=105\end{array}$ & \\
\hline Age, median (IQR), yr & $39(33-50)$ & $36(30-46)$ & $43(37-51)$ & \\
\hline Per 1-yr increase & & & & $0.94(0.91-0.97)$ \\
\hline \multicolumn{5}{|l|}{ Gender } \\
\hline Female & $75(38.3)$ & 29 (31.9) & $46(43.8)$ & $0.60(0.33-1.08)$ \\
\hline Male & $121(61.7)$ & $62(68.1)$ & $59(56.2)$ & \\
\hline \multicolumn{5}{|l|}{ Ethnicity } \\
\hline White & $146(74.5)$ & $68(74.7)$ & $78(74.3)$ & $1.12(0.58-2.16)$ \\
\hline Indigenous/person of colour & $48(24.5)$ & $21(23.1)$ & $27(25.7)$ & \\
\hline \multicolumn{5}{|l|}{ Homeless/unstably housed§ } \\
\hline Yes & $111(56.6)$ & $64(70.3)$ & $47(44.8)$ & $2.93(1.62-5.29)$ \\
\hline No & $85(43.4)$ & $27(29.7)$ & $58(55.2)$ & \\
\hline \multicolumn{5}{|l|}{ Recent incarceration§ } \\
\hline Yes & $24(12.2)$ & $16(17.6)$ & $8(7.6)$ & $2.59(1.05-6.37)$ \\
\hline No & $172(87.8)$ & $75(82.4)$ & $97(92.4)$ & \\
\hline \multicolumn{5}{|l|}{ Sold drugs $\ddagger$} \\
\hline Yes & $63(32.1)$ & $30(33.0)$ & $33(31.4)$ & $1.07(0.59-1.96)$ \\
\hline No & $133(67.8)$ & $61(67.0)$ & $72(68.6)$ & \\
\hline \multicolumn{5}{|l|}{ Engaged in sex work§ } \\
\hline Yes & $38(19.4)$ & $16(17.6)$ & $22(21.0)$ & $0.81(0.39-1.65)$ \\
\hline No & $158(80.6)$ & $75(82.4)$ & $83(79.0)$ & \\
\hline \multicolumn{5}{|l|}{ Usually injected downtown§ } \\
\hline Yes & $51(26.0)$ & $32(35.2)$ & $19(18.1)$ & $2.46(1.27-4.74)$ \\
\hline No & $145(74.0)$ & $59(64.8)$ & $86(81.9)$ & \\
\hline \multicolumn{5}{|l|}{ Usually injected in Old East§ } \\
\hline Yes & $105(53.6)$ & $47(51.6)$ & $58(55.2)$ & $0.87(0.49-1.52)$ \\
\hline No & $91(46.4)$ & $44(48.4)$ & $47(44.8)$ & \\
\hline \multicolumn{5}{|l|}{ Frequent opioid injection§ } \\
\hline Yes & $104(53.1)$ & $62(68.1)$ & $42(40.0)$ & $3.21(1.78-5.78)$ \\
\hline No & $92(46.9)$ & 29 (31.9) & $63(60.0)$ & \\
\hline \multicolumn{5}{|c|}{$\begin{array}{l}\text { Frequent crystal methamphetamine } \\
\text { injection§ }\end{array}$} \\
\hline Yes & $70(35.7)$ & $47(51.6)$ & $23(21.9)$ & $3.80(2.05-7.07)$ \\
\hline No & $126(64.3)$ & $44(48.4)$ & $82(78.1)$ & \\
\hline \multicolumn{5}{|l|}{ Usually injected alone§ } \\
\hline Yes & $106(54.1)$ & $54(59.3)$ & $52(49.5)$ & $1.49(0.84-2.62)$ \\
\hline No & $90(45.9)$ & $37(40.6)$ & $53(50.5)$ & \\
\hline \multicolumn{5}{|l|}{ Needed help injecting§ } \\
\hline Yes & $63(32.1)$ & $31(34.1)$ & $32(30.5)$ & $1.18(0.65-2.15)$ \\
\hline No & $133(67.8)$ & $60(65.9)$ & $73(69.5)$ & \\
\hline \multicolumn{5}{|l|}{ Shared syringe§ } \\
\hline Yes & $44(22.4)$ & $30(33.0)$ & $14(13.3)$ & $3.25(1.59-6.63)$ \\
\hline No & $151(77.0)$ & $60(65.9)$ & $91(86.7)$ & \\
\hline \multicolumn{5}{|l|}{ Ever overdosed unintentionally } \\
\hline Yes & $48(24.5)$ & $28(30.8)$ & $20(19.0)$ & $1.87(0.97-3.63)$ \\
\hline No & $145(74.0)$ & $62(68.1)$ & $83(79.0)$ & \\
\hline \multicolumn{5}{|l|}{ Any substance use treatment } \\
\hline Yes & $83(42.3)$ & $41(45.0)$ & $42(40.0)$ & $1.26(0.71-2.23)$ \\
\hline No & $110(56.1)$ & $48(52.7)$ & $62(59.0)$ & \\
\hline \multicolumn{5}{|c|}{$\begin{array}{l}\text { Note: IQR = interquartile range, OR = odds ratio. } \\
\text { "Except where noted otherwise. } \\
\text { †Columns not adding to total are due to missing values. } \\
\text { flncludes "sometimes," "usually" or "always" injecting in public in the previous } 6 \text { months. } \\
\text { §Over the previous } 6 \text { months. }\end{array}$} \\
\hline
\end{tabular}




\section{Ethics approval}

Ethics approval was obtained from research ethics boards at the University of Toronto and the University of British Columbia.

\section{Results}

Of 199 participants, 196 (98.5\%) provided data pertaining to public injection and are included in this analysis. The sample was predominantly white (146 participants [74.5\%]) and male (121 [61.7\%]) and had a median age of 39 (interquartile range 33-50) years. Characteristics of the study sample stratified by recent regular public injecting, alongside bivariable odds ratios (ORs), are presented in Table 1. Overall, 91 participants $(46.4 \%)$ reported regular public injection $(\geq 25 \%$ of the time) in the previous 6 months. In unadjusted models, age was negatively associated with regular public injection (OR for 1 -yr increase $0.94,95 \%$ confidence interval [CI] 0.91-0.97). Factors positively associated with regular public injection were homelessness or unstable housing (OR 2.93, 95\% CI 1.62-5.29), recent incarceration (OR 2.59, 95\% CI 1.056.37), usually injecting downtown (OR 2.46, 95\% CI 1.274.74), frequent opioid injection (OR 3.21, 95\% CI 1.78-5.78), frequent crystal methamphetamine injection (OR 3.80, 95\% CI 2.05-7.07) and recent syringe sharing (OR 3.25, 95\% CI 1.59-6.63). In the adjusted model (Table 2), homelessness or unstable housing (adjusted OR 2.04, 95\% CI 1.01-4.12), frequent opioid injection (adjusted OR 2.27, 95\% CI 1.17-4.42) and frequent crystal methamphetamine injection (adjusted OR 2.38, 95\% CI 1.18-4.79) remained significantly and positively associated with recent regular public injection.

Among the 141 participants $(71.9 \%)$ who reported any public injection in the previous 6 months, the most common public locations for injecting were washrooms (90 participants [63.8\%]), parks (69 [48.9\%]), parking lots (66 [46.8\%]) and alleys or laneways (61 [43.3\%]) (Table 3). Common reasons provided for injecting in public included convenience (98 participants [69.5\%]), homelessness (56 [39.7\%]) and being too

\section{Table 2: Multivariable logistic regression predicting recent} regular public injecting in London $(n=194)$

\begin{tabular}{|c|c|}
\hline Variable & $\begin{array}{l}\text { Adjusted OR } \\
(95 \% \mathrm{Cl})\end{array}$ \\
\hline Older age (1-yr increase) & $0.97(0.94-1.00)$ \\
\hline Homeless/unstably housed (yes v. no)* & $2.04(1.01-4.12)$ \\
\hline Recent incarceration (yes v. no) ${ }^{*}$ & $1.26(0.45-3.54)$ \\
\hline Usually injected downtown (yes v. no)* & $1.68(0.79-3.61)$ \\
\hline Frequent opioid injection (yes v. no) ${ }^{*}$ & $2.27(1.17-4.42)$ \\
\hline $\begin{array}{l}\text { Frequent crystal methamphetamine } \\
\text { injection (yes v. no)* }\end{array}$ & $2.38(1.18-4.79)$ \\
\hline Shared syringe (yes v. no)* & $1.81(0.80-4.13)$ \\
\hline $\begin{array}{l}\text { Note: } \mathrm{Cl}=\text { confidence interval, } \mathrm{OR}=\text { odds ratio. } \\
{ }^{*} \text { Over the previous } 6 \text { months. }\end{array}$ & \\
\hline
\end{tabular}

far from home (43 [30.5\%]). Recent use of outdoor water sources for preparing drugs or rinsing syringes was reported by 61 participants $(43.3 \%)$.

\section{Interpretation}

We found that, as in larger municipalities, public drug injection is a substantial public health and community-level problem in the mid-sized city of London. The prevalence of any recent public injecting in our sample $(71.9 \%)$ was comparable to findings among people who inject drugs in Canada's largest cities, ${ }^{3,5,6}$ and almost 1 in 2 participants (46.4\%) reported that at least one-quarter of their recent injections took place in public or semipublic settings. Consistent with prior research, ${ }^{1-4,6}$ regular public injecting was independently positively associated with homelessness or unstable housing and high-intensity injection of both opioids and crystal methamphetamine. Although neighbourhood of use was not independently associated with public injecting, crude prevalence was significantly higher among those who reported that they usu-

\section{Table 3: Injection behaviours among those who injected in} public in the previous 6 months

\begin{tabular}{|lc|}
\hline Characteristic & $\begin{array}{c}\text { No. (\%) of } \\
\text { participants } \\
n=141\end{array}$ \\
\hline Frequency of public injecting & $11(7.8)$ \\
\hline Always (100\% of the time) & $37(26.2)$ \\
\hline Usually (75\%-99\%) & $43(30.5)$ \\
\hline Sometimes (25\%-74\%) & $50(35.5)$ \\
\hline Occasionally (<25\%) & \\
\hline Public places injected* & $90(63.8)$ \\
\hline Public washroom & $69(48.9)$ \\
\hline Park & $66(46.8)$ \\
\hline Parking lot & $61(43.3)$ \\
\hline Alley/laneway & $46(32.6)$ \\
\hline Shelter & $44(31.2)$ \\
\hline Abandoned building & $10(7.1)$ \\
\hline Community organization/service provider & $5(3.5)$ \\
\hline Schoolyard & \\
\hline Reason for public injecting ${ }^{*} \dagger$ & $19(13.5)$ \\
\hline Convenient to where I hang out & $61(7.1)$ \\
\hline Homeless & $56(39.7)$ \\
\hline Too far from home & $43(30.5)$ \\
\hline Nowhere to inject safely where I buy drugs & $25(17.7)$ \\
\hline Involved in drug selling & \\
\hline Engaged in sex work & \\
\hline $\begin{array}{l}\text { Used outdoor water source to prepare } \\
\text { drugs or rinse syringes }\end{array}$ & \\
\hline *Participants could select all that applied. \\
\hline †ncludes reasons selected by $\geq 5 \%$ of respondents. \\
\hline
\end{tabular}


ally injected in downtown London, which has important implications for service planning. This may reflect the tendency of people experiencing homelessness or unstable housing to spend time and inject downtown.

\section{Limitations}

This study has several limitations. First, although use of peer recruitment and interviewers contributed to success in reaching a diversity of people who inject drugs (e.g., with respect to gender and race/ethnicity), the sample was not randomly sampled and may not be representative of this population in London. As is common in studies of people who inject drugs, participants were recruited through peer outreach and service provider organizations. Thus, the sampling approach was more likely to capture marginalized people who inject drugs, who may be more likely to inject in public. Second, all data were self-reported and, hence, subject to social desirability bias and recall bias. In particular, reported levels of unintentional overdose appeared low in comparison to other samples of people who inject drugs.

\section{Conclusion}

This study contributes evidence of a substantial burden of public drug injecting in a mid-sized Canadian city. Consistent with findings from Canada's largest cities, public injecting was associated with unstable housing and high-intensity drug use. Supervised injection services and Housing First approaches warrant consideration as interventions to reduce public injecting and its negative consequences for public health and order in London.

\section{References}

1. McKnight I, Maas B, Wood E, et al. Factors associated with public injecting among users of Vancouver's supervised injection facility. Am 7 Drug Alcobol Abuse 2007;33:319-25.

2. Marshall BDL, Kerr T, Qi J, et al. Public injecting and HIV risk behaviour among street-involved youth. Drug Alcohol Depend 2010;110:254-8.

3. DeBeck K, Small W, Wood E, et al. Public injecting among a cohort of injecting drug users in Vancouver, Canada. 7 Epidemiol Community Health 2009;63:81-6.

4. Navarro C, Leonard L. Prevalence and factors related to public injecting in Ottawa, Canada: implications for the development of a trial safer injecting facility. Int 7 Drug Policy 2004;15:275-84.

5. Bayoumi AM, Strike C, Brandeau M, et al. Report of the Toronto and Ottawa Supervised Consumption Assessment Study, 2012. Toronto: St. Michael's Hospital; 2012. Available: www.stmichaelshospital.com/pdf/research/SMH -TOSCA-report.pdf (accessed 2016 Nov. 11).

6. Green T, Hankins C, Palmer D, et al. Ascertaining the need for a supervised injection facility (SIF): the burden of public injecting in Montreal, Canada. $\mathcal{F}$ Drug Issues 2003;33:713-31.

7. Rhodes T, Kimber J, Small W, et al. Public injecting and the need for "safer environment interventions" in the reduction of drug-related harm. Addiction 2006;101:1384-93.

8. Small W, Rhodes T, Wood E, et al. Public injection settings in Vancouver: physical environment, social context and risk. Int 7 Drug Policy 2007;18:27-36.

9. Dovey K, Fitzgerald J, Choi Y. Safety becomes danger: dilemmas of drug-use in public space. Health Place 2001;7:319-31.

10. Kinner SA, Milloy MJ, Wood E, et al. Incidence and risk factors for non-fatal overdose among a cohort of recently incarcerated illicit drug users. Addict Behav 2012;37:691-6.
11. Milloy MJ, Kerr T, Mathias R, et al. Non-fatal overdose among a cohort of active injection drug users recruited from a supervised injection facility. $A m \mathcal{F}$ Drug Alcobol Abuse 2008;34:499-509.

12. Wood E, Kerr T, Small W, et al. Changes in public order after the opening of a medically supervised safer injecting facility for illicit injection drug users. CMA7 2004;171:731-4.

13. Focus on Geography series, 2011 Census. Ottawa: Statistics Canada; 2012. Available: https://www12.statcan.gc.ca/census-recensement/2011/as-sa/fogs -spg/Facts-cma-eng.cfm?LANG=Eng\&GK=CMA\&GC=555 (accessed 2016 Nov. 11).

14. Health regions and peer groups. Ottawa: Statistics Canada; 2013. Available: www.statcan.gc.ca/pub/82-402-x/2013003/regions/hrpg-eng.htm (accessed 2016 Nov. 11).

15. Persons who inject drugs in Middlesex-London: an update. Report no. 040-16. London (ON): Middlesex-London Health Unit; 2016. Available: https://www. healthunit.com/uploads/2016-06-16-report-040-16.pdf (accessed 2016 Nov. 11).

16. Campanella E. More than 2.5 million needles distributed in London last year. London Free Press 2015 Aug. 14. Available: www.lfpress.com/2015/08/13/ more-than-25-million-needles-distributed-in-london-last-year (accessed 2016 Nov. 11).

17. De Bono N. London city hall: consultant calling for downtown crackdown. London Free Press 2016 Oct. 25. Available: www.lfpress.com/2016/10/24/ consultant-calling-for-downtown-crackdown (accessed 2016 Nov. 11).

18. A profile of people who inject drugs in London, Ontario: report on the Public Health Agency of Canada I - Track Survey, Phase 3, Middlesex-London, 2012. London (ON): Middlesex-London Health Unit; 2013. Available: https:// www.healthunit.com/uploads/public-health-agency-of-canada-i-track-survey -phase-3.pdf (accessed 2016 Nov. 11).

19. The impact of prescription and non-prescription drug use in MiddlesexLondon. London (ON): Middlesex-London Health Unit; 2014. Available: https://www.healthunit.com/uploads/2014-05-15-report-032-14.pdf (accessed 2017 Feb. 3).

20. Richmond R. Decrease in London's overdose deaths obscures a growing, longer-term threat from crystal meth. London Free Press 2016 Mar. 17. Available: www.lfpress.com/2016/03/17/decrease-in-londons-overdose-deaths -obscures-a-growing-longer-term-threat-from-crystal-meth (accessed 2017 Feb. 5).

21. Kerr T, Wood E, Small D, et al. Potential use of safer injecting facilities among injection drug users in Vancouver's Downtown Eastside. CMA7 2003; 169:759-63.

Affiliations: Departments of Epidemiology and Biostatistics (Scheim) and of Women's Studies and Feminist Research (Bardwell), Western University, London, Ont.; Ontario HIV Treatment Network (Rachlis, Mitra); Division of Clinical Public Health (Rachlis), Dalla Lana School of Public Health, University of Toronto, Toronto, Ont.; British Columbia Centre for Excellence in HIV/AIDS (Kerr) and Department of Medicine (Kerr), University of British Columbia, St. Paul's Hospital; British Columbia Centre on Substance Use (Bardwell, Kerr), St. Paul's Hospital, Vancouver, BC

Contributors: Thomas Kerr designed the Ontario Integrated Supervised Injection Services Feasibility Study. Geoff Bardwell, Sanjana Mitra and Ayden Scheim acquired the data. Ayden Scheim conducted the analysis and wrote the manuscript. All of the authors contributed to interpretation of findings and revision of the manuscript for intellectual content, approved the final version to be published and agreed to act as guarantors of the work.

Funding: This study was supported by the Canadian Institutes of Health Research (CIHR) Centre for REACH in HIV/AIDS, the Ontario HIV Treatment Network and Thomas Kerr's CIHR Foundation Grant (no. FDN-148476). Ayden Scheim was supported by Pierre Elliott Trudeau Foundation and Vanier Canada Graduate scholarships.

Acknowledgements: The authors thank the study participants, research team and staff (including Elaine Hamm, Andrew MacLean and Samantha Scott) and the study Advisory Committee for their contributions.

Supplemental information: For reviewer comments and the original submission of this manuscript, please see www.cmajopen.ca/content $/ 5 / 2$ / E290/suppl/DC1 